\title{
FILOSOFIA E TRABALHO: UMA REFLEXÃO NO LIMIAR DA SOBREVIVÊNCIA E DA LIBERDADE NO CONTEXTO DA INICIAÇÃO CIENTÍFICA
}

\author{
H. V. BENTES e F. C. L. COIMBRA* \\ Instituto Federal do Pará \\ nanda.lima76@gmail.com*
}

Artigo submetido em outubro/2015 e aceito em dezembro/2015

DOI: $10.15628 /$ rbept.2016.3555

\section{RESUMO}

O objetivo deste artigo é de discutir os dilemas humanos decorrentes do mundo do trabalho, nas perspectivas da sobrevivência material, e também como condição de liberdade, no horizonte da Iniciação Científica dos alunos do Ensino Médio Integrado, disciplina Filosofia, último semestre, eixo estruturante; Filosofia, Trabalho e Iniciação Científica, cursos Informática, Mecânica, Mineração e Telecomunicações, no Instituto Federal de Educação do Pará (IFPA) Campus Belém - semestre 2015/1, em curso. O programa da disciplina Filosofia segue o planejamento curricular regular, porém, no limiar da iniciação científica está em andamento uma pesquisa nas quatro turmas, sob o escopo de que a inserção do método de investigação científica na prática formativa de aprendizes se configura como uma estratégia pedagógico-metodológica de importância crucial, na direção da autonomia reflexiva, visando à formação política e produtiva dos mesmos, no contexto da convivência coletiva. Assim, os resultados preliminares no liminar da iniciação científica, via questionário aplicado aos alunos, apontam que estes reconhecem e valorizam a importância da pesquisa nas atividades escolares com ênfase na produção individual e coletivamente, como elemento constitutivo de autonomia diante do mundo.

PALAVRAS-CHAVE: Filosofia, Trabalho, Iniciação Científica, Sobrevivência, Liberdade, Ensino Médio Integrado.

\section{PHILOSOPHY AND WORK: A REFLECTION ON THE THRESHOLD OF SURVIVAL AND FREEDOM IN THE CONTEXT OF SCIENTIFIC INITIATION}

\begin{abstract}
The purpose of this article is to discuss the human dilemmas arising from the workplace, from the perspectives of survival material, and also as a condition of freedom on the horizon of scientific initiation students of the Integrated Secondary School, Philosophy discipline, last semester, structuring axis; Philosophy, Labor and Scientific Initiation, IT courses, Mechanical, Mining and Telecommunications, the Federal Institute of Education of Para (IFPA) Campus Belém - semester 2015/1, ongoing. The Philosophy course program follows the regular curriculum planning, however, on the threshold of scientific research is ongoing research in four
\end{abstract}

classes, under the scope of the integration of scientific research method in training practice of apprentices is configured as a pedagogical strategy - crucial methodology toward the reflective autonomy, aimed at political and productive formation thereof, in the context of collective coexistence. Thus, the preliminary results of the preliminary scientific research via questionnaire administered to students indicate that they recognize and value the importance of research in school activities with emphasis on individual production and collectively, as a constitutive element of autonomy to the world.

KEYWORDS: Philosophy, Work, Scientific Initiation, Survival, Freedom, Integrated High School. 


\section{APRESENTAÇÃO}

O trabalho é a atividade pela qual a natureza é transformada mediante o esforço coletivo para arar a terra, colher seus frutos, domesticar animais, modificar paisagens e construir cidades. Do trabalho surgem instituições como a família, o Estado, a escola; obras de pensamento como o mito, a ciência, a arte, a filosofia (ARANHA; MARTINS, 2013, p. 54).

No que se refere à política educacional, como uma das políticas públicas do Estado brasileiro, as ações precisam atender as necessidades educacionais, de forma contextualizada, com as outras esferas de participação dos sujeitos que aprendem, objetivando a participação na vida pública (societal) e privada (ética), como estratégias políticas pela/para construção da cidadania coletiva e a efetivação de um projeto de desenvolvimento de nação (BENTES, 2009).

Nesse sentido, muitas estratégias educacionais devem ser (re) construídas, principalmente, pelos canais da democracia, buscando ampliar "[...] a participação dos envolvidos nas esferas das decisões, do planejamento e da execução de políticas educacionais [...]" (HÖFLING, 2001, p. 39).

Como enfatiza Ricardo (2005, p. 9-10) “Há necessidade de repensar as estruturas escolares para atender aos anseios de quem nelas buscam a preparação para as incertezas e ansiedades que o panorama contemporâneo aponta". E neste sentido a iniciação científica no Ensino Médio Integrado pode contribuir para desenvolver nos sujeitos cognoscentes, o espírito e a atitudes de cidadãos autônomos e conscientes das realidades brasileira e global, via escolarização, elevando os níveis de informação e conhecimentos disponíveis sobre ciências, tecnologias e outras dimensões dos saberes da vida prática.

Para isso, é preciso integrar Escola Básica e Universidade públicas à vida dos aprendizes, no que tange a cultura científica, isto é, à maneira científica de produzir conhecimentos e autonomia de decisões, no cotidiano da vida produtiva e no terreno das relações de cidadania.

\section{A IMPORTÂNCIA DA FORMAÇAO INTEGRAL NO ENSINO MÉDIO INTEGRADO}

Se a educação básica é o processo pelo qual às pessoas têm acesso aos conhecimentos e à cultura da sociedade em que vivem, por outro lado, a formação específica, que em nosso sistema educacional se nomeou como "educação ou formação profissional", as pessoas se apropriam de conhecimentos relacionados mais imediatamente com o mundo da produção, Ramos (2005, p. 108). Nesta conjuntura - o que é o trabalho como meio de sobrevivência e, como condição de liberdade?

Ante essa questão, Karl Marx1 (APUD ARANHA; MARTINS, 2013, p. 382) reforça que o trabalho como condição de liberdade tem nas forças da Natureza e do Homem, um processo de transformação, aonde o homem modifica a natureza para atender às suas necessidades, mas, ao mesmo tempo, a natureza modificada, humaniza o homem ao transformá-lo, em sujeito de criação (trabalho), na condição de sujeito de cultura (recriação).

Na fronteira dessa questão; a formação integral na perspectiva de potencializar a formação cidadã, de forma imbricada com a preparação à vida socialmente produtiva; e concomitante, a

\footnotetext{
${ }^{1}$ Marxismo, doutrina econômica e filosófica iniciada por Karl Marx e Friedrich Engels, que tem como fundamento o materialismo histórico e dialético (ARANHA; MARTINS, 2013, p. 382).
} 
metodologia de iniciação científica podem contribuir enormemente, se utilizadas como mediadoras entre os fatos, fenômenos e objetos no mundo; e o sujeito cognoscente, numa relação de enfrentamento, compreensão e superação de desafios nas esferas dos significados (LUCKESI; PASSOS, 2002).

\section{O TRABALHO COMO CONDIÇÃO DE SOBREVIVÊNCIA E DE LIBERDADE HUMANA NO CONTEXTO DA INICIAÇÃO CIENTÍFICA}

O conceito de trabalho como uma atividade que altera o estado material das coisas existentes e, que pela ação humana se transforma em objetos úteis, que passam a ter utilidade, pode ser considerado como resultante da intervenção do homem na natureza. Esse processo é concebido como resultado da idealização da mente homo sapiens, que podemos denominar de trabalhador (BRAVERMAN, 1987).

Além desse conceito genérico, o trabalho pode ainda, ser analisado enquanto uma categoria ontológica, e assim encarado como produção cultural, ou seja, como resultado das representações humanas, mediada pela linguagem, subjetividade e pela capacidade raciocinada de criar e recriar a sua própria realidade, a partir da acumulação do progresso da cultural material (BRAVERMAN, 1987; SAVIANI, 1989).

Ainda podemos refletir sobre a concepção de trabalho, como "força de trabalho", e, por esse viés, caracteriza-se como o recurso exclusivo da humanidade para enfrentar a natureza.

Nesse contexto, é importante diferenciar duas categorias sociais de análise que são fundamentais à compreensão da realidade subjacente ao mundo do trabalho na perspectiva do modelo de produção capitalista vigente.

O conceito de divisão social do trabalho como o sistema complexo de todas as formas úteis diferentes de trabalho; e o outro conceito é o de divisão de trabalho entre trabalhadores, que se dá num ambiente parcial de produção, cujo resultado é uma produção coletiva, realizada por trabalhadores atuando de forma individualizada, à qual podemos denominar de mercadorias.

A partir dessas premissas, apresenta-se a divisão social e técnica do trabalho como consequência de um modelo de produção (capitalista), no qual prevalece uma estratificação determinada por interesses definidos e contratuados sob a relação de assalariamento.

Assim, uma classe é detentora do capital e dos meios de produção, e a outra é possuidora apenas da força de trabalho, que se torna a fonte geradora de mercadorias e da riqueza.

Essa relação contratual selada pela compra da força de trabalho cria no sistema de produção capitalista a superação da identidade do trabalhador, enquanto proprietário da sua própria produção, ou seja, o resultado da sua ação não contempla o seu esforço físico e criativo, ele não é mais dono de si mesmo, na estrutura produtiva, agora parcializada.

Dessa forma, as transformações no mundo do trabalho desencadeiam dilemas humanos no âmbito da sobrevivência e das condições de liberdade, novas formas de sociabilidade, de intervenções educativas, no sentido mais amplo possível (função da ideologia, alienação, desigualdades de toda ordem), e nas práticas comportamentais. 
A atividade trabalho é desvinculada da identidade do trabalhador. Essa fragmentação do "ser" trabalhador, pelo viés da atividade produtiva, aliena o sujeito produtivo da obra produzida, pois a obra produzida tem um preço que não equivale às condições de produção, o trabalhador não detém o processo 'inteiro' de produção, e a obra não lhe pertence materialmente, e nem como vontade de liberdade (opção de comprá-la, de fazer o quê quiser - alienação). A teoria do valor ${ }^{2}$ não condiz com a sua condição potencial de sujeito autônomo.

Além disso, a produção caminha ao processo de automação da produção, o que configura um processo crescente de independência do capital, que agora não é mais situado, é volátil. 0 trabalhador perde cada vez mais espaço no mercado de trabalho, e em decorrência dessa situação é lançado à condição de desempregado (BENTES, 2009 e 2013).

O emprego no cenário automatizado impõe como exigência um perfil novo de trabalhador, que pela lógica do capital em estágio de reprodução, mediado pelo discurso ideológico, por sinal muito eficiente, embute na divisão social do trabalho a ideia de que para estar incluído no mundo do trabalho, e não no mercado de trabalho, o sujeito tem que dominar novos conhecimentos e enquadrar-se num perfil polivalente e, portanto, flexível às necessidades da produção em larga escala, em tempos de globalização.

Dessa forma, a divisão do trabalho, amplia a sua esfera pela internacionalização do trabalho. As "competências" exigidas do trabalhador são as condições atuais para estar no mercado de trabalho, e a taxonomia também muda, agora não é mais emprego, é empregabilidade (OLIVEIRA, 2003) a condição para sobreviver com "dignidade". A ideologia política chamada neoliberalismo, faz muito bem essa articulação para o capital em expansão.

A produção burguesa não tem vistas à coletividade trabalhadora, agora, a tecnologia é o instrumento de medida da produção. Portanto, a riqueza é o resultado do processo tecnológico, a força do trabalhador é vista como valor agregado, o trabalhador deixa de ser o ator principal, e passa a fazer papel de coadjuvante, isso na perspectiva, dos defensores do fim da centralidade do trabalho, como Adam Schaff e André Gorz (APUD. ANTUNES, 2001 e PRIEB, 2000).

Como consequência dessa nova forma de produção, os níveis de desemprego aumentam, assim como aumenta a riqueza nas mãos de poucos (desigualdades extremas, alta concentração de rendas e capitais nas mãos de poucos), nas asas das competências (OLIVEIRA, 2006) polivalentes conduzidas por uma estrutura produtiva autônoma (leis do mercado) mediada por trabalhadores "competentes", guiados pelas sutilezas do neoliberalismo (ANDERSON, 1996) pautado na concorrência "salutar", sem a intervenção do aparelho estatal; que deve ater-se apenas, à regulação das relações jurídicas, ou seja, advogar à legalidade do desenvolvimento do capital globalizante. Desta maneira, o Estado se fragiliza na sua função premente de gerador, equalizador do Bem Comum, da Justiça Social.

Nesse contexto de precariedade, o trabalho perde a sua condição ontológica de 'capacidade de sobrevivência da espécie' e assume o papel de regulador das oportunidades de mercado. A empregabilidade é a nova metodologia de acesso e de "sucesso" na vida. O trabalho visto a partir deste ângulo perde a sua centralidade, enquanto forma humana produtiva e pré-

\footnotetext{
2 Segundo essa teoria, o valor económico de uma mercadoria é determinado pela quantidade de trabalho que, em média, é necessário para a produzir, incluindo aí todo o trabalho anterior (para produzir suas as matérias primas, máquinas, etc.). Disponível em: < http://pt.wikipedia.org/wiki>. Acesso em 26 maio, 2015.
} 
requisito à cidadania coletiva, de sobrevivência digna, e de pressuposto da liberdade de ser livre para fazer escolhas.

A partir dessa análise unilateral e caótica da categoria trabalho, a expectativa de sobrevivência seria humanamente impossível, e a liberdade uma utopia.

Diante dessa realidade, tornam-se imprescindível, a priori, algumas reflexões no contexto da Filosofia na Educação Básica e Profissional, modalidade integrada, que contemple à existência humana, nas múltiplas formas de expressão, seja social, ética, política e cultural. De maneira que, não limite essas formas de existir, ao restrito segmento da produção econômica, ou seja, do sistema produtivo.

$\checkmark$ Qual é o papel da escola nesse cenário atual?

$\checkmark$ Qual a concepção de homem e de trabalho devem nortear a ação educadora?

$\checkmark$ Que sujeito ela deve formar?

$\checkmark$ Qual é o princípio que deve guiar as intervenções educativas de professores e alunos, enquanto problematizadores da vida prática?

$\mathrm{Na}$ fronteira desses questionamentos foi aplicado um questionário aos alunos das quatro turmas de Filosofia, última etapa do Ensino Médio Integrado no IFPA Campus Belém, em 2015/1, perguntando: como a metodologia de iniciação científica poderia ajudá-los a compreender melhor a realidade prática, com os estudos das temáticas da Filosofia e do trabalho?

E as respostas preliminares dos alunos apontaram que $69 \%$ deles compreendem que as atividades escolares de pesquisa em grupo facilitam a troca de ideias, de pontos de vista, e que apuram a reflexão sobre o cotidiano.

Também foi perguntado aos alunos como eles se sentiram - ANTES, DURANTE e DEPOIS, das atividades em público, resultantes da aplicação da metodologia de iniciação científica?

E nesse cenário emergiram depoimentos significativos no que tange ao trabalho individual e em grupo, no âmbito da autonomia: $53 \%$ dos alunos envolvidos nas atividades afirmaram que se sentiram desafiados ANTES das atividades em público; $53 \%$ se sentiram seguros DURANTE as apresentações em público (na sala de aula); e 67\% deles declararam que se sentiram realizados DEPOIS da apresentação pública aos colegas da sala.

Os resultados preliminares sugerem que a iniciação científica foi/pode ser uma metodologia do dia a dia nas salas de aula, nas disciplinas da matriz curricular de todos os cursos no Ensino Médio Integrado, independente de área de conhecimento. E mais, que a iniciação científica pode aproximar a Educação Básica da Universidade. Afinal, a formação dos cidadãos brasileiros não deve trilhar percursos separados em termos de conhecimentos, habilidades e vida prática, no âmbito das políticas públicas.

Esse desafio de integrar Escola Básica e Universidade encontra-se ainda enviesado nas perguntas: qual é o papel da escola nesse cenário? Que concepções de homem e trabalho devem nortear a ação educadora? Que sujeito formar? Qual é o princípio que deve guiar as intervenções educativas de professores e alunos, enquanto problematizadores da vida prática?

As Política Pública do Estado brasileiro, sobretudo, precisam alicerçar a construção e implementação contínua da Formação Pública de Qualidade, nas dimensões pedagógicas, políticas, éticas e culturais, de forma imbricada, com as questões macro-políticas, forjadas na 
estrutura estatal, nas trincheiras polarizantes das classes sociais, no espectro da sociedade civil, e na participação ético-comunitária dos sujeitos sociais, na mais ampla acepção da Soberania do Estado e da Sociedade Civil.

Na confluência dessa questão, o escopo da metodologia de iniciação científica no Ensino Médio Integrado, como prática regular, pretende alcançar algumas premissas básicas necessárias à construção de um projeto pedagógico-político mais autêntico, e que materialize novas "formas de educações" (PRETTO e PINTO, 2006), à convivência e produção/criação humana, no limiar da Educação enquanto uma política pública emancipatória, que efetive "[...] qualidade política na população, ao propiciar o saber pensar, a autonomia, a aprendizagem e o conhecimento de teor reconstrutivo político" (DEMO, 2006, p. 93).

No âmbito da Escola Pública, como parte dos agentes institucionais, a Constituição Federal, 1988, “Art. 227. É dever da família, da sociedade e do Estado assegurar à criança, ao adolescente e ao jovem, com absoluta prioridade, o direito à vida, à saúde, à alimentação, à educação, [...]", este princípio constitucional, dialoga com o pensamento de Spagnol (2013, p. 117) que apresenta uma das diretrizes centrais da Instituição escolar pública, de "educar para a cidadania, de forma permanente, continuada e global, a partir de Valores Humanos, visando atingir mentes e os corações, através da igualdade entre educadores e educandos".

Daí, não é possível aceitar que a escola pública seja utilizada com reprodutora do sistema de desigualdades sociopolíticas e, utilizada estrategicamente, como ambiente restritivo de formação para o mercado de trabalho, sob a lógica tirânica do acesso - os que têm acesso; têm oportunidades de trabalho e vida digna.

Sair dessa lógica deve ser um compromisso perseguido pelas famílias dos alunos, pelos servidores públicos da Educação, pela Escola Pública, pela Sociedade Civil e pelo Estado Democrático de Diretos, no limiar de uma Política Pública de Educação, à (ao):

- Construção democrática, pela/para cidadania e formação Profissional no nível médio formação integral;

- o trabalho como princípio ontológico da constituição humana e da sociabilidade ética e solidária;

- compreensão/consubstanciação das categorias Trabalho e Educação como convergentes e complementares;

- o processo educacional como critério de inclusão e cidadania coletiva;

- educação de qualidade à universalização de direitos, que não fique restrita a critério de acesso ao mercado de trabalho.

Nessa mesma direção estão as reflexões de Carvalho (2003, p. 130), sobre a possibilidade da pedagogia do trabalho ser concretizada na concepção de escola unitária. Em suas palavras:

A escola unitária é aquela que integra em sua organização a educação infantil, o ensino fundamental e médio, neste incluído a educação profissional e é, a única, capaz de viabilizar a formação integral e politécnica do trabalhador.

Portanto, uma escola que contemple a existência humana, nas múltiplas formas de expressão, seja social, ética, política e cultural, e que não limite essas formas de existir, ao restrito segmento da produção econômica, ou seja, do sistema produtivo. 
A partir dessa premissa, o processo de Iniciação Científica dos alunos na última fase da Educação Básica - o Ensino Médio Integrado torna-se uma intervenção necessária e estratégica, na direção do desenvolvimento das capacidades e habilidades intelectuais, imaginativas daqueles, no terreno da autonomia, das relações interpessoais, e na expressão dos seus valores internos e externos, via processos de comunicabilidade, nas dimensões individuais (morais) e coletivas (éticas) da cidadania.

Às perguntas iniciais: que concepções de homem e trabalho devem nortear a ação educadora? Qual é o papel da escola nesse cenário atual? Que sujeito ela deve formar? Qual é o princípio que deve guiar as intervenções educativas de professores e alunos, enquanto problematizadores da vida prática?

As políticas públicas devem convergir na direção de espaços emancipatórios que favorecem a convivência democrática das diferentes populações, e ao exercício da liberdade de expressão nas dimensões da crítica e da autocrítica, no sentido da (re) reconstrução política dos sujeitos que aprendem na convivência social.

No âmbito da Escola Pública, a questão do acesso e manutenção dos direitos constitucionais, e da criação de espaços pedagógicos de vivências das diferenças, de maneira democrática e ética: educação permanente, continuada e global, sem descaracterizar os traços culturais locais; e sem esvaziar o princípio da igualdade entre educadores e educandos, enquanto aprendizes contumazes.

Quanto às intervenções educativas de professores e alunos, sob a metodologia de iniciação científica regular na Escola Básica, potencializam melhorias à convivência democrática, nas múltiplas formas de expressão, seja social, ética, política e cultural, para além da reprodução do sistema econômica, regido pela lógica funcional do mercado de trabalho.

A metodologia de iniciação científica permite o desenvolvimento reflexivo e crítico de aprendizes cognoscentes, isto é, sujeitos temporais que entendem o mundo e transformam suas atitudes, o próprio mundo e melhoram as relações de sobrevivência e liberdade.

Práticas educativas dessa natureza metabolizam capacidades e habilidades intelectuais, imaginativas, criativas de educadores e educandos, nas dimensões da autonomia, das relações interpessoais, e na expressão dos seus valores internos e externos, via processos de comunicabilidade, esferas individuais (morais) e coletivas (éticas) da cidadania.

Com relação à questão problema: o que é o trabalho como meio de sobrevivência e, como condição de liberdade? O trabalho é uma condição e produção humana, porque consciente, mas é também uma opção declaratória em termos de escolha de projeto societário. Portanto, um posicionamento político diante das mazelas de um sistema de produção capitalista, que se mostra e se metamorfoseia em ciclos de reprodução de capitais, ora locais, ora globais, e na emergência gritante de desigualdades sociais nas asas de altas concentrações de rendas, nas mãos de poucos, para os quais tudo parece ser possível e contável (monetário).

\section{REFERÊNCIAS}

1. ANDERSON, Perry. Balanço do neoliberalismo. In: SADER, Emir \& GENTILI, Pablo. Pósneoliberalismo: as políticas sociais e o Estado democrático. São Paulo: Paz e Terra, 1996, 
p. 9 a 37.

2. ANTUNES, Ricardo (2001). Reestruturação capitalista e mudanças no mundo do trabalho numa ordem neoliberal. In: DOURADO. Luiz \& PARO, Vitor (Org). Políticas públicas e educação básica. São Paulo: Xamã, p. 13 a 27.

3. ARANHA, Maria Lúcia de Arruda; MARTINS, Maria Helena Pires. Filosofando: introdução à filosofia. 5a ed. - São Paulo: Moderna, 2013.

4. BENTES, Haroldo de Vasconcelos. Concepção e Prática do Ensino Medio Integrado: a percepção dos professores da ETF - Palmas - Tocantins. Mestrado - Universidade de Brasília - Faculdade de Educação, UnB, 2009, p. 138 f. Disponível em: <http://www.bdtd.bce.unb.br>. Acesso 08 maio, 2015.

5. Tecnologias digitais e a prática pedagógica do PROEJA, no Instituto Federal de Educação, Ciência e Tecnologia do Pará, campus Belém. Doutorado - Universidade Federal do Ceará - Faculdade de Educação, UFC, 2013, p. 266 f. Disponível em: <http://www.repositorio.ufc.br>. Acesso 08 maio 2015.

6. BRASIL. Constituição da República Federativa do Brasil de 1988. Disponível em: <http://www.planalto.gov.br>. Acesso em: 11 de julho 2015.

7. DECRETO 5154/04 - Regulamenta o § 2ㅇ do art. 36 e os arts. 39 a 41 da Lei $n$ o 9.394, de 20 de dezembro de 1996, que estabelece as diretrizes e bases da educação nacional, e dá outras providências.

8. BRAVERMAN, Harry. Trabalho e capital monopolista: a degradação do trabalho no século XX. 3 ed. Rio de Janeiro: livros técnicos e científicos, 1987.P P. 49-60

9. CARVALHO, Olgamir F. Educação e formação profissional - trabalho e tempo livre. Brasília: Plano Editora, 2003.

10. DEMO, Pedro. Pobreza política: a pobreza mais intensa da pobreza brasileira. São Paulo: Autores associados, 2006.

11. HÖFLING, Eloísa de Mattos (2001). Estado e políticas (públicas) sociais. In: Políticas públicas e educação. Cadernos CEDES. Campinas: CEDES, n. 55, p. 30 a 41.

12. LUCKESI, Cipriano Carlos; PASSOS, Elizete Silva. Introdução à filosofia: aprendendo a pensar. 4. ed.São Paulo: Cortez, 2002

13. MEDEIROS, João Bosco. Redação científica: a prática de fichamento, resumos, resenhas. 6.ed. São Paulo: Atlas, 2004.

14. Normas ABNT em vigência Disponíveis para consulta na Biblioteca Central ASSOCIAÇÃO BRASILEIRA DE NORMAS TÉCNICAS (14842). NBR 6028: informação e documentação resumo - apresentação. Rio de Janeiro, 2003.

15. OLIVEIRA, R. A (Des)qualificação da educação profissional brasileira. 1. ed. São Paulo: Cortez, 2003. $96 \mathrm{p}$.

16.

Empregabilidade. In: Escola Politécnica de Saúde Joaquim Venâncio e Estação de Trabalho Observatório de Técnicos em Saúde. (Org.). Dicionário da educação profissional em saúde. 1. ed. Rio de Janeiro: EPSJV, 2006, v. , p. 141-146.

17. PRETTO, N. L. ; PINTO, Claudio da Costa . Tecnologias e Novas Educações. Revista Brasileira de Educação, São Paulo, v. 11, n. 31, p. 19-30, 2006. 
18. PRIEB, Sérgio. A tese do fim da centralidade do trabalho: mitos e realidades. Artigo acadêmico. Economia e desenvolvimento, no. 12, novembro/2000.

19. RAMOS, Marise. CIAVATTA, Maria. FRIGOTTO, Gaudêncio. (orgs.). Ensino Médio Integrado: concepções e contradições. São Paulo: Cortez, 2005.

20. RICARDO, Elio C. COMPETÊNCIAS, INTERDISCIPLINARIDADE E CONTEXTUALIZAÇÃO: Parâmetros Curriculares Nacionais a uma compreensão para o ensino das ciências. Tese apresentada ao Programa de Pós-Graduação em Educação Científica e Tecnológica, da Universidade de Santa Catarina (UFSC), 2005, p. 9/10.

21. SAVIANI, Dermeval. 0 trabalho como princípio educativo frente às novas tecnologias. Sobre a Concepção de Politecnia. R. J.: Fiocruz, 1989.

22. SPAGNOL, Antonio Sergio. Sociologia Jurídica. São Paulo: Saraiva, 2013. 